\title{
EFFECT OF HYDROGEN ADDITION ON FLAME PROPAGATION CHARACTERISTICS THROUGH TUBE OF METHANE-AIR MIXTURES USING OPTICAL TECHNIQUE.
}

\author{
ARKan F. SAID \\ Dept. of Mechanical Engineering, College of Engineering, University of Duhok, Kurdistan Region-Iraq
}

\begin{abstract}
The effect of Hydrogen addition on laminar flame speed $\left(U_{f}\right)$ of Methane - Air premixed mixtures using optical technique has been experimentally investigated inside a tube. The flame front location had been positioned by a photocell. The $\left(U_{f}\right)$ measured at a laboratory conditions for an extensive range of equivalence ratios $(\Phi)$. In order to use density ratio method for the calculation of laminar burning velocity $\left(U_{L}\right)$, all experimental work was carried out at constant pressure (Pre-pressure period). The flame temperature $\left(T_{b}\right)$ has been calculated theoretically. Mixture strength $(\Phi)$ and hydrogen content $\left(R_{H}\right)$ dependence of $\left(U_{L}\right)$ is represented by empirical correlation over the ranges $\Phi=(0.6-1.4), R_{H}=(0,0.1,0.2,0.3,0.4)$, all at initial unburned mixture temperature $T_{u}=298 \mathrm{~K}$ and a pressure of $(1 \mathrm{~atm})$. In overlapping ranges, the results were found in satisfactory agreement with those previously published.
\end{abstract}

KEYWORDS: Premixed flame, Methane, Hydrogen, Laminar Burning Velocity, Flame speed.

\section{INTRODUCTION}

M any researchers have measured the laminar burning velocity of various hydrocarbon fuels to investigate the mechanism of flame propagation [Gibbs and Calcote (1959)] [1], and to validate the thermo-kinetic models and reaction mechanisms of hydrocarbon combustion. The laminar burning velocity is a physicochemical constant parameter for a given combustible mixture. Although its theoretical definition is simple, unfortunately the same cannot be said of its practical measurement, [Hamid and Said, (2001)] [2].

Hydrogen offers high flame speeds, which as a result to high burning velocities for a wide flammability range, low minimum ignition energy and no emissions of $\mathrm{HC}$ or $\mathrm{CO}_{2}$ [Boushaki, T., et al. (2012). [3], and Ilbas, M., (2006) [4]. Boushaki, T., et al. (2012) [3], used the slot burner method to measure the $U_{L}$ and COSILAB code using GRI-Mech 3.0, in calculations for characterizing the effects of hydrogen and steam addition on methane-air combustion over a wide range of operating conditions. Milton and Keck (1984) [5], experimentally investigated the $U_{L}$ of hydrogen, acetylene, and methane gas mixtures using a spherical combustion bomb. Also, for the same mixtures, a simulated combustion product in various proportions has been made from elevated range of $T_{u}$ and pressures.
Yu, G., et al. (1986) [6], used symmetrical, adiabatic, counter-flow arrangement to determine the flame speeds of methane + air and propane + air mixtures, with and without the addition of stoichiometrically small amount of hydrogen. Their results show that $U_{f}$ were increased with hydrogen addition. Also, their results linearly correlated with the $U_{f}$ without hydrogen addition and a single parameter indicating the extent of hydrogen addition.

Coppens, F.H.V., et al. (2007) [7], presented experimental measurements of adiabatic $U_{L}$ and NO formation in methane + hydrogen + air flames. Non-stretched flames were stabilized on a perforated plate burner using the Heat flux method to determine $U_{L}$ under conditions when the net heat loss of the flame is zero. A correlation for adiabatic $U_{L}$ of methane + hydrogen + air mixtures at standard conditions has been derived.

Arkan F. Said (2012) [8], presents experimental work using propagation inside tube for Methanol and Ethanol - Air mixtures using the density ratio method presented by Andrews and Bradley (1972b) [9]. The initial temperature and number of carbon atoms dependence of burning velocity had been represented by empirical correlation, which can be used for certain conditions within $( \pm 5 \%)$ error certainty.

The present work uses more advanced technique, which has been established for the first time in the country. The optical technique used in 
measuring the $U_{f}$ and $U_{L}$ for methane - air mixtures for a physical limitation of hydrogen percentage enrichment under standard conditions.

\section{EXPERIMENTAL METHODOLOGY}

The flame propagation rig used for these experiments has been intensively explained previously in [Hamid and Said, (2001)] [2]. Briefly, it is a copper tube of $(192 \mathrm{~cm})$ length, (10 $\mathrm{cm})$ inner diameter and $(6 \mathrm{~mm})$ thickness. In order to control the initial mixture temperature, a high thermal conductivity of copper was used to heat the mixture to a certain temperature. Fig. (1), elucidates the rig used in present work. Preparing operation plays an important role in amelioration of the combustion phenomenon. The present operation was made depending on the partial pressures of the constituents according to GibbsDalton's law. A closed mixing vessel designed for the purpose of preparing operation to increase the total pressure of the methane - air mixtures consequently increasing the partial pressure of gaseous fuel. Fig. (2), illustrates the details of mixing unit. Around the tube, a heating tape was located for heating the mixture to the desired initial temperature, which was measured by a thermocouples located at the center of the tube.

After mixture preparation and measuring the initial temperature, the flame kernel was produced by ignition unit. Four photocells were fixed at certain points along the tube, in order to measure $\left(U_{f}\right)$ of the gases mixture under consideration using photocell technique. The distance between two adjacent photocells was $(25 \mathrm{~cm})$. Some preparations were taken into consideration in localizing the first photocell from the spark plug in order to ensure that all measurements occur at fully developed flame front. Two channel digital storage oscilloscopes were used to record the signals from the photocells for measuring the flame speeds.

\section{EXPERIMENTAL RESULTS AND DISCUSSION}

Figure (3) presents the measured mean flame speed of methane - air mixture with different percentage of hydrogen enrichments. The density ratio method that introduced by Andrews and Bradley (1972a) [9], were used to calculate the $U_{L}$ from measured $U_{f}$. The methodology used as the following equations:

$$
\begin{aligned}
U_{L} & =\frac{\beta_{b}}{\beta_{u}} \cdot U_{f} \\
\frac{\beta_{b}}{\beta_{u}} & =\frac{T_{u}}{T_{b}} \cdot M_{r} \cdot F_{t h}
\end{aligned}
$$

Where;

$\beta_{u}$ : Density of unburned gases $\left(\mathrm{kg} / \mathrm{m}^{3}\right)$.

$\beta_{b}$ : Density of burned gases $\left(\mathrm{kg} / \mathrm{m}^{3}\right)$.

Mole ratio $=$ moles of unburned gases

$M_{r}$ : in equilibrium per moles of burned gases.

$F_{\text {th }}:$ Flame thickness factor.

The magnitudes of $\left(M_{r}\right)$ and $\left(F_{t h}\right)$ have been calculated depending on the relations of the Andrews and Bradley (1972b) [10]. Fig. (4) and Fig. (5), show the variation of $\left(M_{r}\right)$ and $\left(F_{t h}\right)$ with $(\Phi)$. Adiabatic $T_{b}$ was calculated using the equation of Gülder, O.L., (1986) [11] as shown in Fig. (6). $U_{L}$ has been calculated from:

$$
U_{L}=\frac{T_{u}}{T_{b}} \cdot M_{r} \cdot F_{t h} \cdot U_{f}
$$

The flame thickness $(\delta)$ shown in fig. (7), was calculated according to the formulation presented in Spalding, D.B., et al. (1971) [12] as the following equation:

$$
\delta=\frac{2 \bar{\lambda}}{U_{L} \cdot \bar{C}_{P} \cdot \beta_{u}}
$$

\section{BURNING VELOCITY}

The experiments of the present work were conducted with the methane - air at a pressure of $(1 \mathrm{~atm})$ and $(T u=298 \mathrm{~K}) .\left(U_{L}\right)$ of different $(\Phi)$ is illustrated in fig. (8), where the data points represent the mean value of more than ten repetitive experiments. The methane fuel exhibit a maximum $U_{L}$ on the rich side near to $(\Phi \cong 1.1)$ under atmospheric conditions.

A comparison was established for methane fuel with the previously published works as shown in fig. (9). The results exhibited a good agreement with the published data. As noticed, the low measured burning velocities most probably from the wall quenching effect of the combustion tube walls, which is discussed in details in references $[9,10]$. 
The $\left(U_{L o}\right)$ variation at laboratory conditions varying with $(\Phi)$ as follows:

\section{$U_{L o}=-3.3249-78.076 . \Phi+252.21 . \Phi^{2}-132.58 . \Phi^{3} \ldots$ \\ HYDROGEN ENRICHMENT EFFECT ON BURNING VELOCITY}

The hydrogen content effect on burning velocity is illustrated in figures (10) and (11) as an examples of $\left(R_{H}=0.1\right.$ and 0.2$)$. The equivalence ratio and hydrogen content are the most two parameters to be used to indicate the methane and hydrogen concentrations. Figures (12) and (13) illustrating an alternate plot of $\left(U_{L o}\right)$ with $\left(R_{H}\right)$ being the independent variable, and $(\Phi)$ the parameter. It can be noticed that $\left(U_{L o}\right)$ vary linearly with $\left(R_{H}\right)$ over the range of $(\Phi)$ under investigation. Also, the slopes of the curves do not vary too much from each other.

Based on the behavior of figures (11) and (12), it is logically to correlate $\left(U_{L o}\right)$ according to the following equation:

$$
U_{L}=U_{L_{o}} \cdot\left(1-R_{H}\right)^{\alpha}
$$

Where $\left(R_{H}\right)$ is the hydrogen concentration varying from $(0,0.05,0.1, \ldots, 0.4)$, and the exponent $(\alpha)$ varying with the equivalence ratio. $(\alpha)$ has been introduced by fitting the data using least squares method. The results are as follows:

$\alpha=-4.9421+5.5786 . \Phi-0.5338 . \Phi^{2}-1.2887 . \Phi^{3} \ldots$

\section{CONCLUSION}

The burning velocity variation of methane - air mixture as a function of mixture strength and hydrogen addition has been determined experimentally using the tube method and advanced optical technique which is a modern technique in this field. The density ratio method that introduced by Andrews and Bradley [9] has been used in the present work analysis.

The hydrogen addition effect on burning velocity can be represented by the following empirical correlation:

$$
U_{L\left(\Phi, R_{H}\right)}=U_{L o(\Phi)} \cdot\left(1-R_{H}\right)^{\alpha}
$$

Where;

$$
U_{L o(\Phi)}=-3.3249-78.076 . \Phi+252.21 . \Phi^{2}-132.58 . \Phi^{3}
$$

And:

$$
\alpha=-4.9421+5.5786 . \Phi-0.5338 . \Phi^{2}-1.2887 . \Phi^{3}
$$

Which can be used with an error $\cong \pm 5 \%$ for the following conditions:

$$
\begin{aligned}
& \Phi=(0.6-1.4) \text { and } \boldsymbol{R}_{\boldsymbol{H}}=(0,0.05,0.1, \ldots, 0.4) \\
& \text { Po }=1 \mathrm{~atm} \\
& \text { Tu }=298 \mathrm{~K}
\end{aligned}
$$

Figure (14) represent a three dimension configuration of the results of the established equation. Where the laminar burning velocity $\left(U_{L}\right)$ as a function of mixture strength $(\Phi)$, for several values of hydrogen enrichment $\left(R_{H}\right)$.

\section{REFERENCES}

[1] Gibbs, G.J. and Calcote, H.F., (1959), "Effect of molecular structure on burning velocity". J. Chem. Eng. Data. Vol.4, No.3, July, pp.226237.

[2] Hamid, M.N. and Arkan, F. Said, (2001), "The effect of initial temperature on burning velocity of methane, propane, LPG and IsoButane-air mixtures". Eng. J. Univ. Qatar, Vol.14, pp. 177192.

[3] Boushaki, T., Dhue, Y., Selle, L., Ferret, B., and Poinsot, T., (2012). Effect of hydrogen and steam addition on laminar burning velocity of methane-air premixed flame: Experimental and numerical analysis. Int. J. Hydrogen Energy, 37: 9412-9422.

[4] Ilbas, M. Crayford, A.P., Yilmaz, I., Bowen, P.J., and Syred, N. (2006). Laminar burning velocities of hydrogen-air and hydrogenmethane-air mixtures: an experimental study. Int. J. Hydrogen Energy, 31(12): 1768-1779.

[5] Milton, B.E., and Keck, J.C., (1984). Laminar Burning Velocities in Stoichiometric Hydrogen and Hydrogen-Hydrocarbon Gas Mixtures. Combustion and Flames, Vol. 58, pp.13-22.

[6] Yu, G., Law, C.K., and Wu, C.K., (1986). Laminar Flame Speeds of Hydrocarbon+Air Mixtures with Hydrogen Addition. Combustion and Flames, Vol. 63, pp.339-347.

[7] Coppens, F.H.V., De Ruyck, J., and Konnov, A.A., (2007). Effect of hydrogen enrichment on adiabatic burning velocity and NO formation in methane + air flames. Experimental Thermal and Fluid Science (Elsevier), 31, pp.437-444. 
[8] Arkan, F. Said, (2012), "The effect of initial temperature on burning velocity of Methanol and Ethanol-Air mixtures". ARPN J. of Eng. and Applied Sci., Vol.7, No.10, October, pp. 1307-1313.

[9] Andrews, G.E. and Bradley, D. (1972a). Determination of burning velocity. a critical review. Combustion and Flames, Vol. 18, pp.133-153.

[10]Andrews, G.J. and Bradley, D., (1972b). The burning velocity of methane-air mixtures. Combustion and Flame, Vol.19, pp.275-288.
[11]Gülder, O.L., (1986), "Flame temperature estimation of conventional and future Jet fuels". J. Eng. for Gas Turbines and Power, Vol. 108, April, 376-380.

[12]Spalding, D.B., Stephenson, P.L., and Taylor, R.G., (1971). A Calculation procedure for the prediction of laminar flame speeds. Combustion and Flames, Vol. 17, pp.55-64.

[13] Hamid, M.N. and Arkan, F. Said, (2007), "The effect of initial temperature on burning velocity of hydrogen-air mixtures". J. Eng. and Technology, Vol.25, No.2, pp. 183-194.
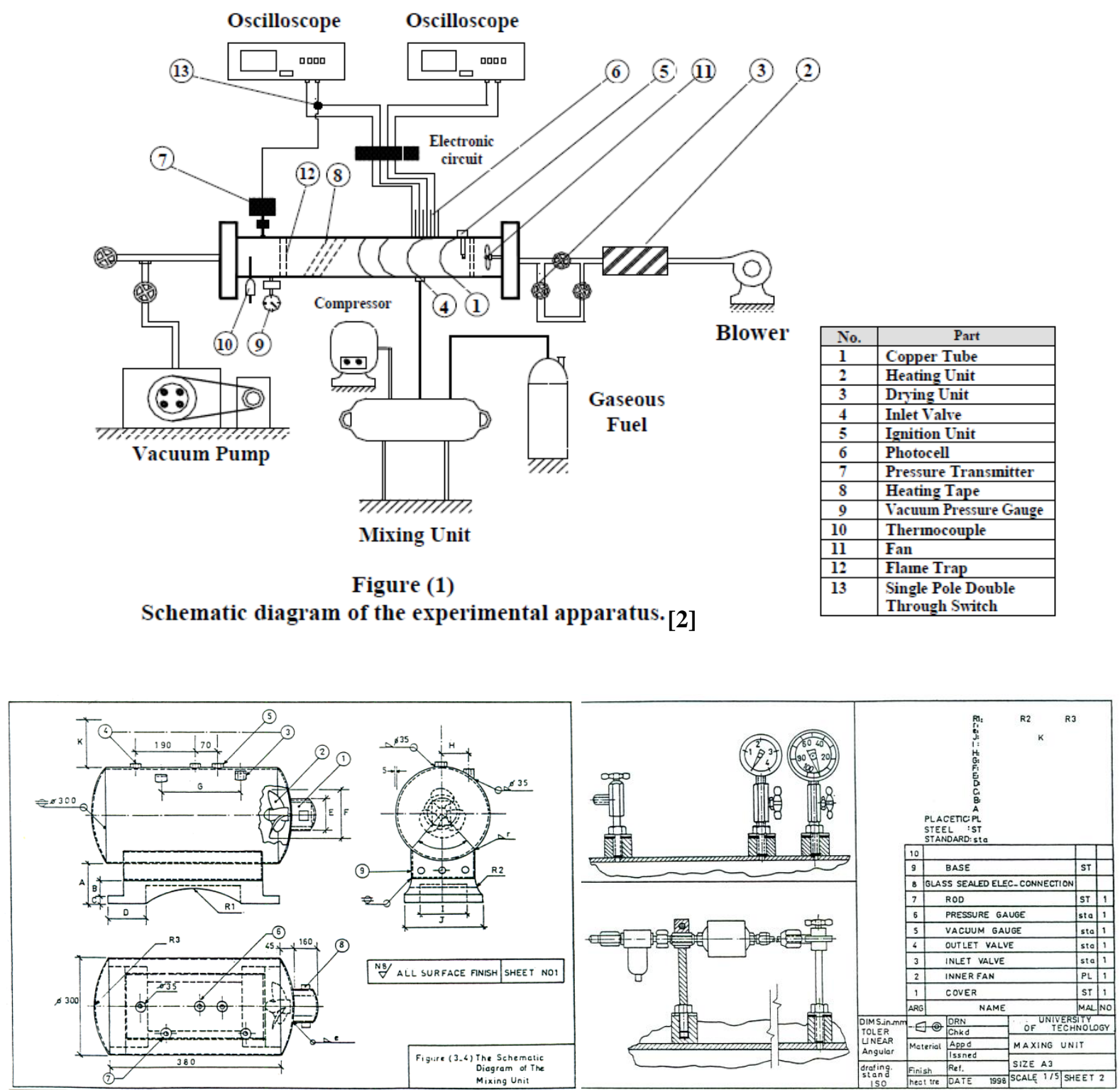

Fig.(2): Schematic diagram of the Mixing unit [2] 


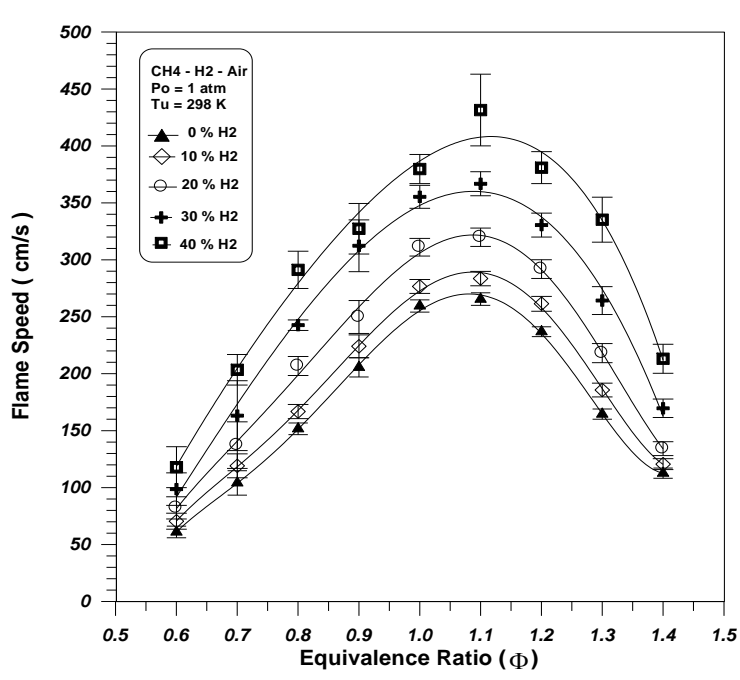

Fig. (3): Mean flame speed variation with equivalence ratio for different hydrogen enrichment percent.

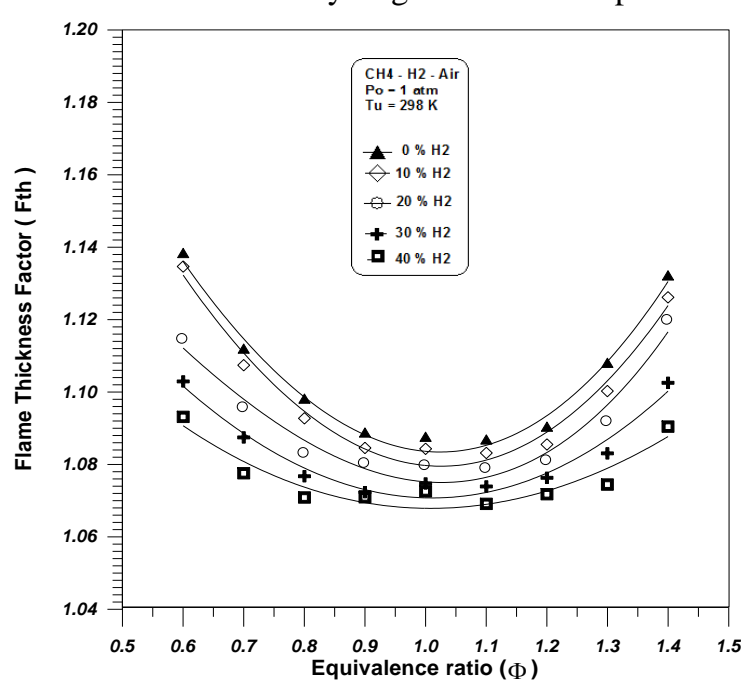

Fig. (5): Flame thickness factor variation with equivalence ratio.

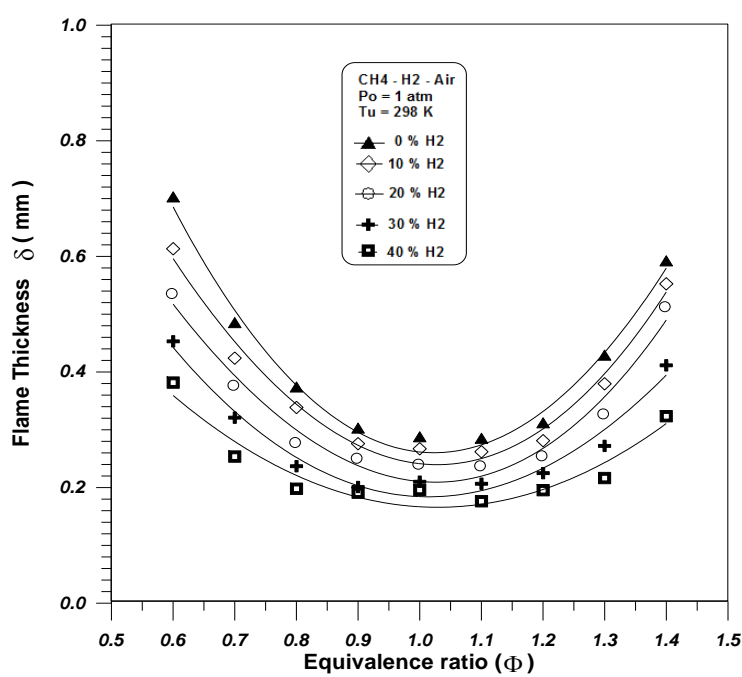

Fig. (7): Flame thickness as a function of eauivalence ratio.

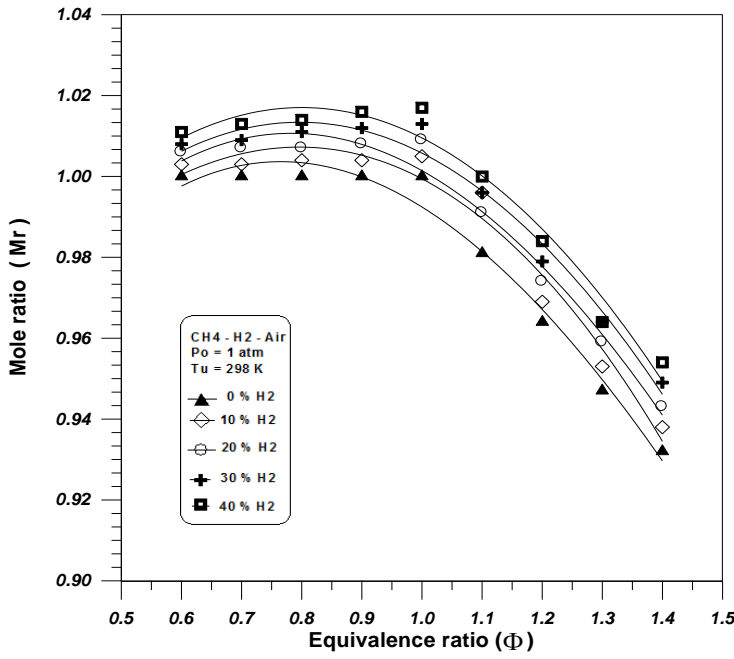

Fig. (4): Mole fraction variation with equivalence ratio.

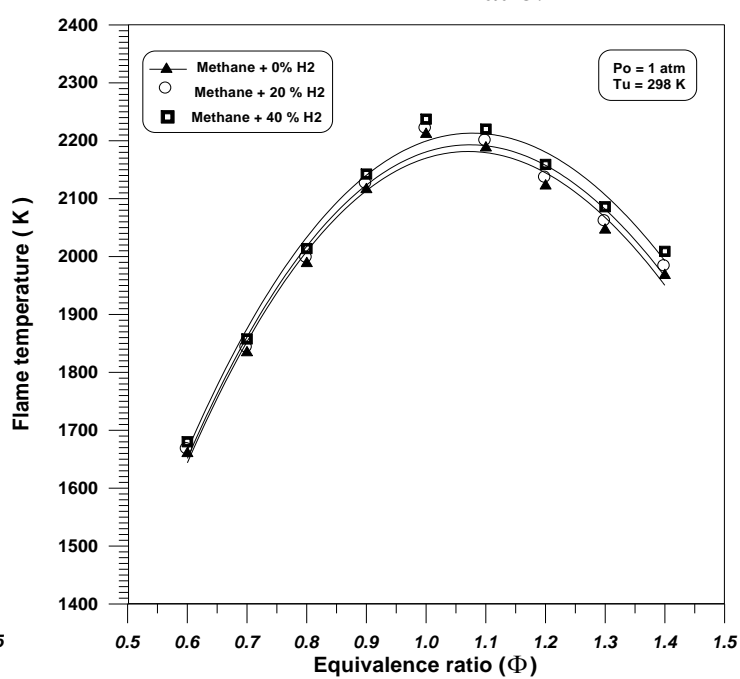

Fig. (6): Adiabatic Flame temperature as a function of equivalence ratio.

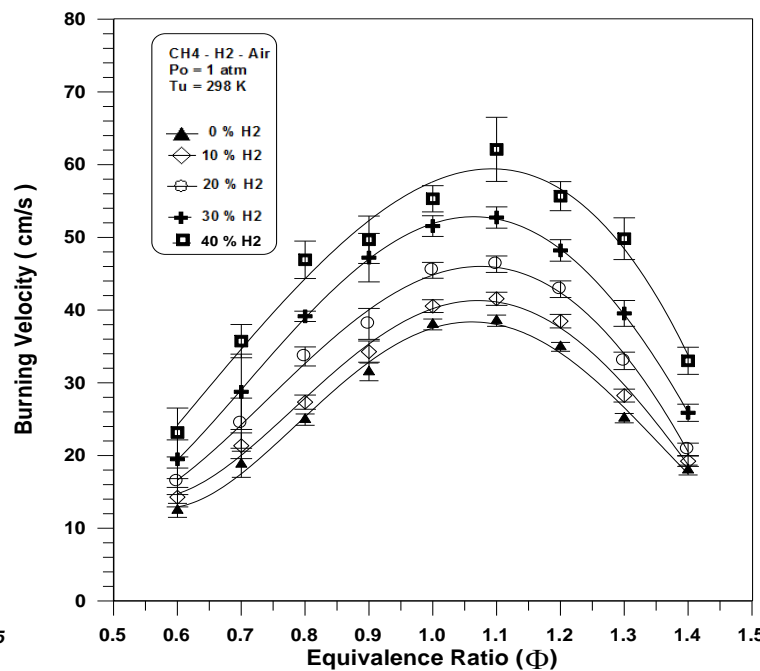

Fig.(8): Burning velocity variation with equivalence ratio for different hvdrogen enrichment nercent 


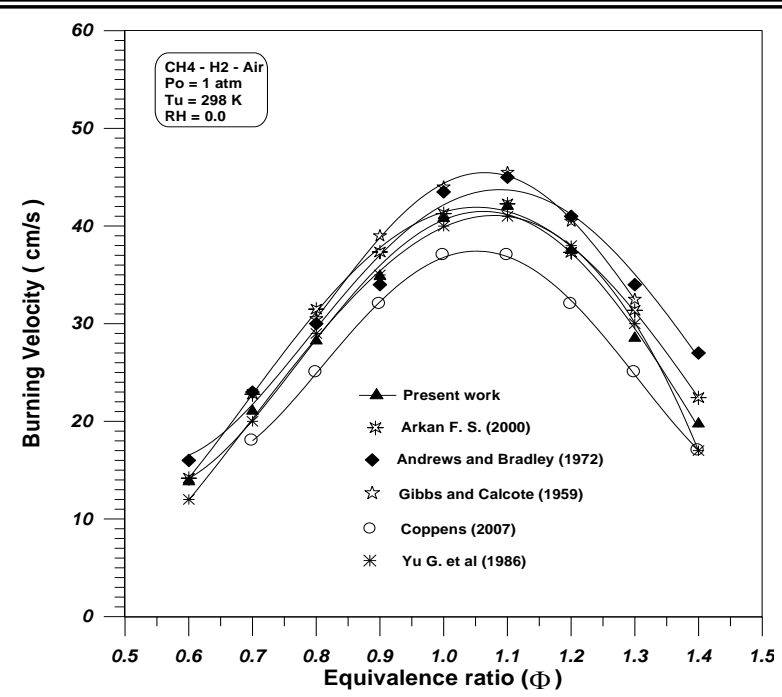

Figj (9): Comparison of present results with the published results without hydrogen enrichment.

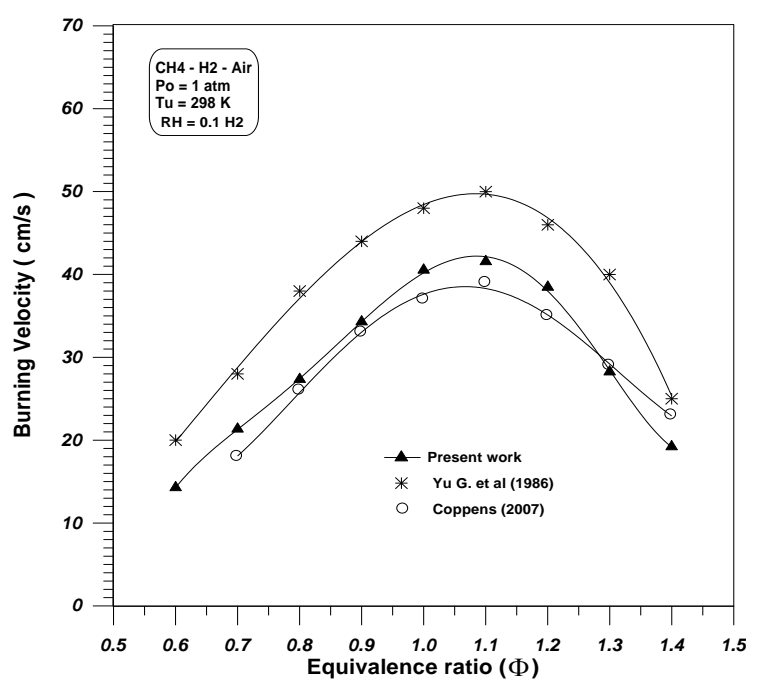

Fig. (10): Comparison of present results with the published results with hydrogen $\mathrm{RH}=0.1$.

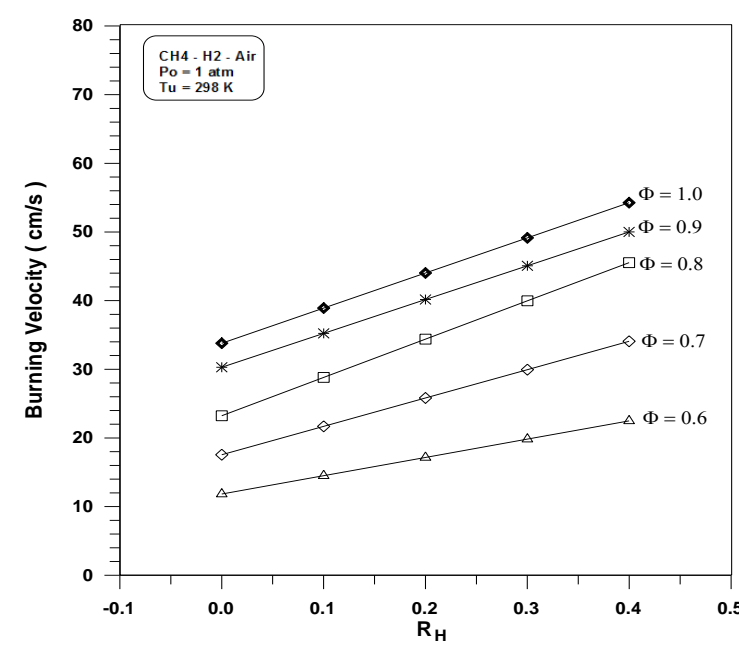

Fig. (12): Variation of burning velocity with hydrogen content $\mathrm{RH}$ in weak mixture strength.

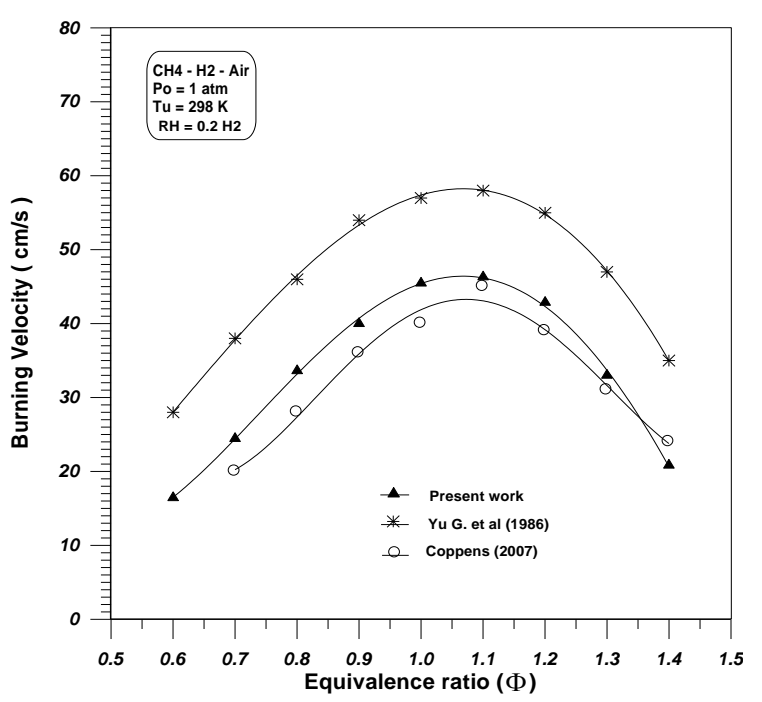

Fig. (11): Comparison of present results with the published results with hydrogen $\mathrm{RH}=0.2$.

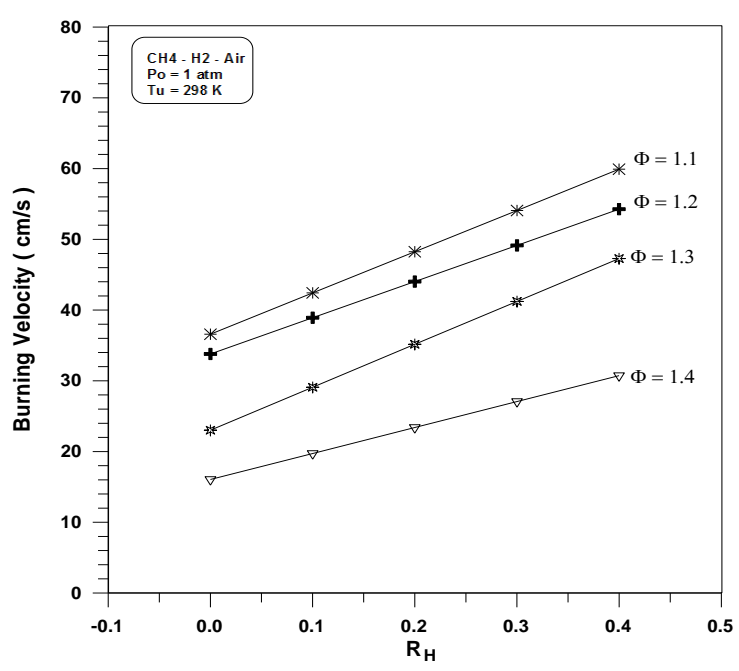

Fig. (13): Variation of burning velocity with hydrogen content RH in rich mixture strength. 


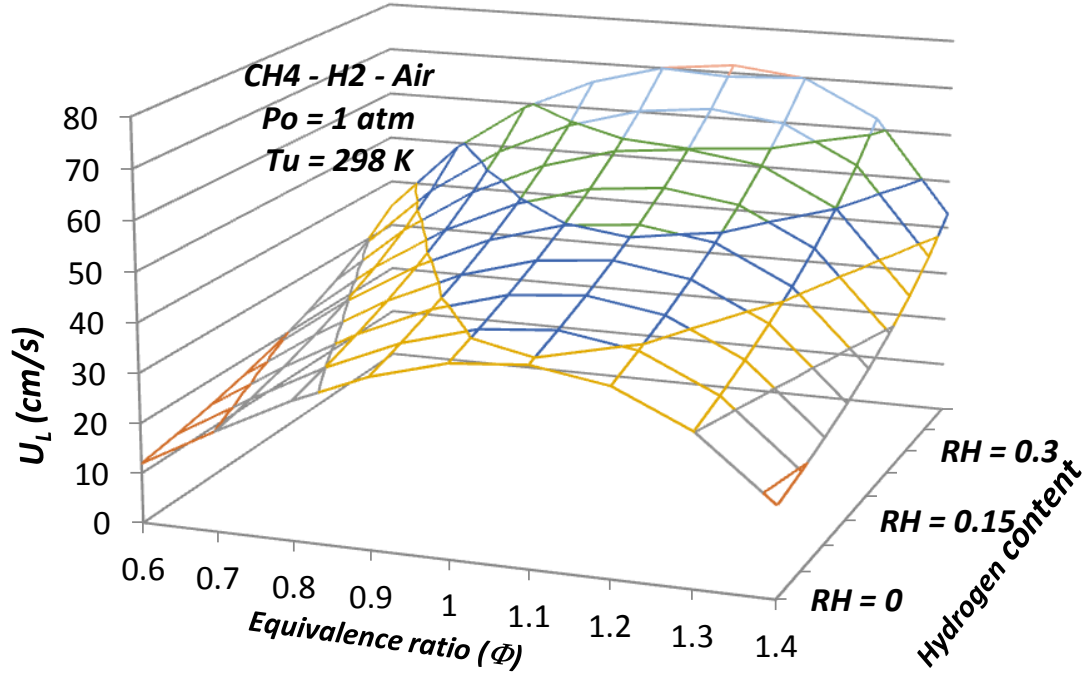

Fig. (14): Three-dimensional representation of burning velocity dependence on equivalence ratio and hydrogen enrichment. 